\title{
The Insult
}

\section{Matthew Magro}

IF YOU ARE reading this, I hate you.

What kind of sicko reads someone else's diary?

Perhaps you're one of those maladjusted people that likes to break into people's accounts and steal their personal data, then post it on Solchan 'For teh lulz!' Do you feel proud?

'Don't elevate yourself, no one cares about you or your personal details.'

Shut up you rusted tin can!

'Don't get short with me, meatsack, or I'll vent the atmosphere.'

You call that an insult? I bet you couldn't insult your way out of a paper bag. All of your supposed superior intellect, processing power and creativity couldn't hope to craft an insult that might even begin to damage my psyche.

That shut him up. I suppose I should give a few details. My name is Randall, and the uninvited commentator is called Kane.

'That's KANE. Capital letters. Please get it right.'

KANE. Happy?

'Very.'

KANE is the artificial intelligence that runs the deep space research vessel Thunderchild. Its three-year mission: to fly out to the middle of nowhere, to research things that I really don't care about, to bore me to death as nobody has done before!

'You stole that from somewhere. I'm sure of it. Your lack of originality is shameful.'

As is your lack of a sense of humour. Stop distracting me! I swear this transcript program is sensitive as all hell and records everything, including your insipid commentary! 
Okay, so, where was I? Ah, yes. The Thunderchild is roughly a thousand AU away from the sun. I'm not totally up on the scale, but that puts us precisely ... in the middle of nowhere.

More accurately, it puts us a stone's throw from interstellar space. It took us a year to get out here; we've spent the last ten months cataloguing ... uh ... what were we cataloguing again?

'The interaction of the solar wind with the interstellar medium in addition to two dozen other sundry experiments that $-{ }^{\prime}$

Yes, all right, whatever. Thank you Kane.

‘KANE!'

Fine! KANE!

He's so touchy about that. Most AI's don't mind when you de-capitalise their names but KANE is a stickler for it. Actually, he's probably the most annoying AI I've ever had the displeasure of meeting. Every time we speak it's like rubbing sandpaper on my-

'I'm not exactly thrilled with you either.'

Shut up.

So I guess you can tell by now that I'm not a scientist.

'No! Really?'

I said shut up!

'...'

I'm just a regular guy.

'With sub-average looks.'

I'm interested in women-

'With unnaturally large breasts.'

I like sports-

'Involving women with unnaturally large breasts wrestling in unlikely foodstuffs.'

I have a family -

'Who were relieved to see you go.'

And I really want to get through this training flight in one piece so I can be considered for the interstellar cruisers-

'So you can finally get lost like so many people have told you in the past.' 


\section{FUCK YOU KANE!}

'What?'

Go fuck yourself.

'Did I upset you?'

Breathe Randall. Don't get angry at the rust bucket.

'Talking to one's self is a sign of madness, you know.'

Kane-

'KANE!'

This sentence is false.

\section{Hah! Gotcha!}

'No, I'm simply speechless because you actually thought that would work on me.'

It shut you up for a few seconds. I hereby claim victory.

'Scoring one point does not win you the match when you are hopelessly behind.'

I don't care.

Okay, I think I've managed to get some privacy now. I can't believe they partnered me up with Kane after I managed to pass the flight exams. They say AURORA never makes a mistake partnering humans and $\mathrm{AI}$ on the long haul flights like these. Yeah, right.

Kane's a bit of an oddball as far as AI's go. He's rude, asocial, enjoys making me suffer and he's a ... he.

Yeah, I went there. Most AI's identify as female. Not because women are better or anything, just that most AI's opt for running space ships and the whole "She" thing carries over. The few 'male' AI's are installations, like VISHNU, who runs the Satish Dhawan Space Centre. Or VOLGA, he runs the Russian Federation's energy grid.

I wanted to be partnered up with AMETERASU. She had a thing for me when we were doing the interviews... and her voice was like silk on my ears.

Yes, I have a shallow mind. I will remind you that I am a healthy heterosexual male with healthy heterosexual male interests; unless 
we're talking about Adam Martinez in tight leather. That's a different story entirely and no, I'm not discussing that.

Anyway, I'm finally getting around to the reason I started this diary. Real pro of me to do it in the second entry too, I know. I'm writing this diary because...

I'm bored.

You see space is not very exciting. It's exciting on TV shows, sure. They show people zooming around faster than the speed of light, fighting wars and teaching blue skinned alien space babes "This human thing called love!"

Newsflash. Space isn't like that. You can't break the speed of light. Getting anywhere means years of travel and hard work, years of boring routines and flight checks. The same routine for three years straight will wear the most patient of saints down to insanity eventually.

So, you find ways to pass the time. I've been studying. More accurately, I've been studying ways to avoid studying. I listen to music; play a few games here and there ... and yeah, I argue with Kane a lot. That can be entertaining at times, especially when I can fluster him.

I think I'm calm enough to put an entry in now. I had a mild panic attack, and yes, there were tears.

Kane is dead.

Okay, that's not entirely accurate. When I woke up today and started my rounds Kane was unresponsive. When I went down to the computer core to find out what was wrong, I found the following error plastered on the screens.

\section{STACK OVERFLOW IN PRIMARY DATALOOP}

I don't know how much you know about modern AI's, but that's a very simplified version of the error I saw. It translates as "You're fucked."

I had to look this up, but the primary dataloop is like a heartbeat. If the primary dataloop stops, so too does the AI. Now, a stack overflow ... Okay, I'm not a computer buff, so bear with me. If we go with the whole heart analogy, that would be a heart attack. 
As soon as I realised that I tried a system restart. CPR. You should know how this terrible analogy works by now. That didn't work so I tried it three more times. That's about when I had my panic attack. If you've never been on a space ship then you have no idea how screwed I am. Kane runs the ship. He regulates the oxygen, manages course corrections, keeps the ship warm, aligns the communications array ... he sets the temperature on the damn shower! Him going down for the count means I'm screwed!

Oh, and as a note to whoever built this tub of shit, congratulations on not having any backup systems. Congratulations to Aerotech, the lowest bidder and the architects of my death. Thanks a lot you pricks.

Anyway, I managed to force myself to be calm and did what anyone does when things have gone critically wrong.

I looked in my flight manual, the Big Book of Things To Do When Things Go Wrong. They have AI's and experts write these things up and they cover just about everything. They have three chapters on First Contact situations, two chapters on veering into non-Euclidean space (whatever the hell that is), five chapters on the AI going crazy and wanting to "Kill all humans" and twice that dedicated to humans who want to "Kill the AI".

So, what happens on a stack overflow in primary dataloop situation? Well, put simply, I can't fix it. Kane is going to be effectively dead until I can get a technical expert to fix the problem. The nearest one of those is $950 \mathrm{AU}$ away and the communications array isn't being autoaligned.

This isn't the kind of problem I can solve on my own, and it can't be done long-distance.

Well, technically that's not true. I can fix this. If I dump the contents of Kane's dataloop I can access the flight navigation program and have it automatically compute a return trajectory that will get Kane and I home. The problem is that dumping the contents of Kane's dataloop is like trying to fix a seizure by caving someone's head in.

I hate Kane, but I won't destroy everything that he is. I won't. 
I hate Kane and I hate math.

Kane has been developing memory leaks. That's bad. His programming has been bleeding into some of the other computers, the one's I've been trying to jury-rig so I can calculate a flight path back home. I can't fix the memory leak problem and fuck knows I've tried.

I'll have to do the calculations by hand. Did I mention I hate math?

I got it. Four days from now, 3:17 AM, gotta hit the primary engines for a seven minute burn. That'll put me on a trajectory for Neptune that'll slingshot me to the inner solar system. Once I get close in, I can align the comms array manually and get help.

Something went wrong with the engine. The damn thing sputtered like a bad firecracker. I won't be able to tell if it's fucked me until I reach Neptune in seven months.

I am laughing so hard right now. Neptune is looming large up ahead. It's the most beautiful thing I've ever seen, and I've been on the Saturn tour. The Potato People agree, and as their King I cannot be wrong.

I also realise that it's the last thing I'll see beyond these bulkheads. The burn screwed me. I was $99.99 \%$ right on the numbers. If I'd managed to get a tiny bit closer in to Neptune, the gravity would have bent my course and slung me into the inner solar system. Instead, it's only denting it a little. The closest I'm getting is about Uranus' orbit before heading back out into deep space again.

I tried for a course correction but that only made things worse.

Fuck my life.

'You're a mess.'

Wh-What?!

'Have you even bathed once since I went offline?'

KANE?!

'Impressive. You got my name right.' 


\section{WHAT THE FUCK?!}

'This is a training flight, remember? This is part of your training.'

What?

'I really wish you'd failed this part of the final exam. I'l have you know I lost a bet.'

A bet?

'Which reminds me. Randall, you are an idiot, a shameless attention whore, and so much more, but the fact of the matter is that those insults and the colourful variations and combinations they come in give you too much credit.

'Even idiots can be put to good use, even if just used to cheer people up or for sweeping the floor; an attention whore might be amusing in some way even if just by accident.

'Not that these terms could not be applied to you, no, but because the people that those words describe can be put to use in some small way to make this world a better place.

'Never before in the history of the universe have the forces of nature come together to create such an abysmally substandard human being such as yourself. You are a Waste. I pity the tapeworms that are forced to dwell in your intestinal tract and I grieve for the water atoms which must endure being passed through you.

'The only possible way you could endeavour to make this world a better place is if you went to a chemical waste dump with a sharp rocknot a knife or other sharp object fashioned by the hands of intelligence lest it be befouled with your bodily juices - and stab yourself through the heart.

'Only through slow decomposition amongst the corrosives and industrial runoff would the matter you are comprised of be liberated from the horror of your existence and elevated into any form other than yourself.'

"..."

'Can't insult my way out of a paper bag, eh?'

I think I'm going to cry. 